\title{
A Gender Analysis Of Health Policy In Pakistan
}

\author{
Shagufta Nasreen \\ \& \\ Aliyah Ali \\ Women's Studies \\ University of Karachi
}

\begin{abstract}
Pakistan is signatory to international commitments to promote gender equality and equity. This has seen introduction of a number of gender mainstreaming policy initiatives in the last ten years. Despite these initiatives gender mainstreaming still needs a lot to do in all sectors of policy. Therefore, aim of this research is to analyze the policies of health sector and analyze the extent to which it has been adapted to gender needs. For secondary analysis the original policy documents and other reports and studies related to the health sector were analyzed. Gender Reform Action Plan (GRAP) was also analyzed which is the main instrument through which the government of Pakistan seeks to address the deep rooted gender inequality in Pakistani society. Analysis shows that the redressing discrimination on gender biasness is necessary to ensure equality and equity to less class privileged groups. Results also show that in health policy the gender component is included but superficially. If policies do not consciously aim to reduce inequalities as their primary target, whether these inequalities are in the form of income/asset distribution, in access to effective social protection, or by way of legal citizenship rights, these policies will necessarily result in discrimination. Eliminating the social and economic hurdles that obstruct equality must be the foundation of every policy intention, otherwise policy initiatives will merely end up duplicating and reinforcing existing discrimination against marginalised sectors, especially women, minorities and the poor.
\end{abstract}

Keywords: Gender Analysis, Health Policy.

$$
\begin{aligned}
& \text { تلخيص }
\end{aligned}
$$

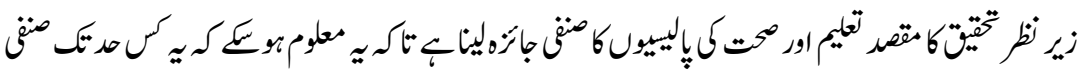

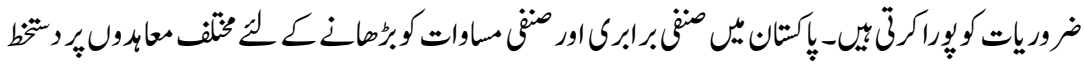

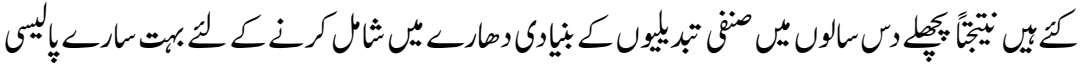

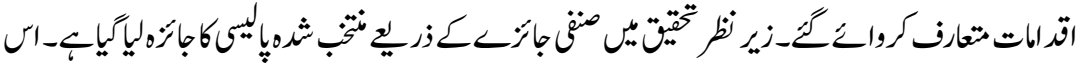

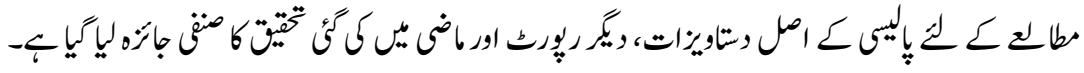

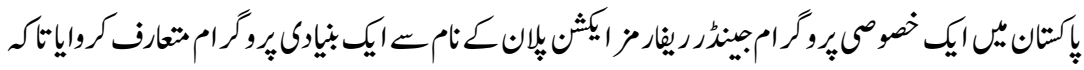




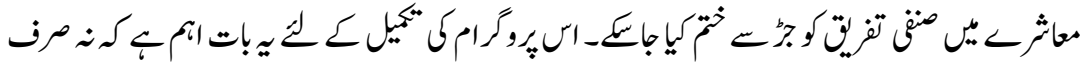

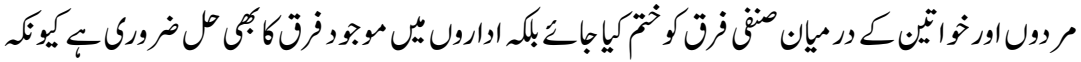

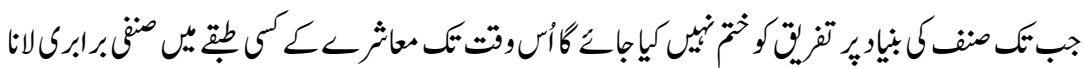

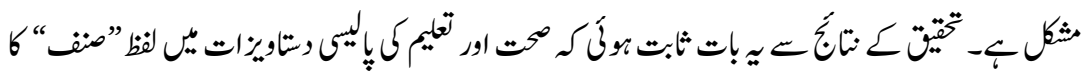

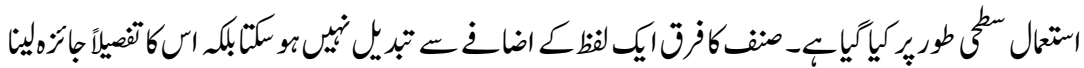

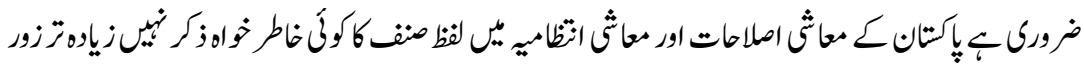

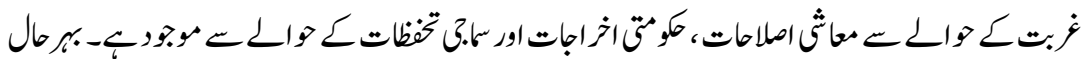

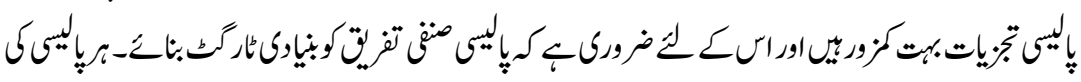

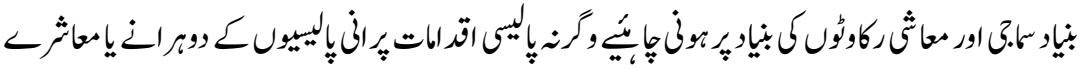

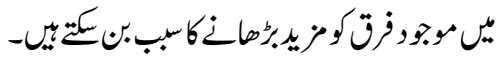

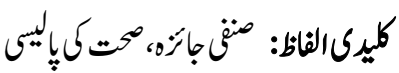

\section{Introduction}

The successive governments in Pakistan, especially during the last two-and-a-half decades or so, have been increasingly concerned that the disadvantaged position of Pakistani women is not only inequitable but also constrains the achievements of country's development potential. They, at different points of time, have shown their commitment to redressing this waste of human and development potential. Quite a sizeable number of programs and policy measures regarding women development such as of their socio-political and economic empowerment; have been instrumental in bringing about a considerable improvement as compared to the situation prevailing even 20 years ago.

The un-imperative status of women in Pakistani society, internationally encounter as a breach of human rights and an obstacle towards development. Since decades the women position is only recognized as a subordinate and oppressed has been marginalized to social structure of life. The social life has constrained women in important areas such as training, employment, looking after house hold chores. As a result, the content or priorities of such socials institutions reflect the male supremacy in the name of powerful and privileged in social and cultural system. In the case of health, women's social, economic and political status tends health as a matter of not important. Analyzing of gender inequity, whether in the relations between men and women or in institutions, need to be recognized and addressed. Therefore, the redressing the discrimination on gender biasness is necessary to ensure equality and equity to less class privileged groups. The process of assessing the implications for women and men of any planned action, 
including legislation, policies or programmes, in any area and at all levels becomes necessary.

Gender analysis is a strategy for making women's as well as men's concerns and experiences an integral dimension in the design, implementation, monitoring and evaluation of policies and programmes in all political, economic and social spheres, such that inequality between women and men is not perpetuated. Gender analysis, that is, an examination of the relationships and role differences between women and men, is the first step of a mainstreaming strategy. Gender analysis identifies analyses and informs action to address inequalities that arise from the different roles of women and men, or the unequal power relationships between them and the consequences of these inequalities on their lives, their health and well-being. The way power is distributed in most societies means that women have less access to and control over resources to protect their health and are less likely to be involved in decision-making. Gender analysis in health therefore often highlights how inequalities disadvantage women's health, the constraints women face to attain health and ways to address and overcome these constraints. Gender analysis also reveals health risks and problems which men face as a result of the social construction of their roles (WHO, 2003).

In the recent past, internationally, many efforts have been made to include gender in programmes and policies in public sector. The process is called Gender mainstreaming. It is "Mainstreaming gender is both a technical and a political process which requires shifts in organizational cultures and ways of thinking, as well as in the goals, structures and resource allocations. Mainstreaming requires changes at different levels within institutions, in agenda setting, policy making, planning, implementation and evaluation. Instruments for the mainstreaming effort include new staffing and budgeting practices, training programmes, policy procedures and guidelines"( WHO, 2003).

This research paper is to do a gender analysis of selected policies in Pakistan where the GDI rank lowest of all countries. This study explains and evaluates the gender related problems in Pakistan that depict gender inequalities. The reason behind it is the socio economic, political and cultural barriers that manifest the women participation. This paper will examine the areas of critical gender inequalities in Pakistan. It also discusses the current policies and the programs addressing the gender issues in Pakistan and to ensure some policy to improve the women's status in Pakistan.

In an era characterized by heightened globalization and increasingly radical state restructuring, the question of gender equality has become acute. Scholars of international relations offer a number of theoretical explanations for the crossnational convergence of ideas, institutions, and interests. We examine the 
proliferation of state bureaucracies for gender mainstreaming. These organizations seek to integrate a gender-equality perspective across all areas of government policy. Although they so far have received scant attention outside of feminist policy circles, these mainstreaming bureaucracies - now in place in over 100 countries-represent a powerful challenge to business-as-usual politics and policymaking. As a policy innovation, the speed with which these institutional mechanisms have been adopted by the majority of national governments is unprecedented. We argue that transnational networks composed largely of nonstate actors (notably women's international nongovernmental organizations and the United Nations) have been the primary forces driving the diffusion of gender mainstreaming. Findings of True and Mintrom (2001) support the claim that the diffusion of gender-mainstreaming mechanisms has been facilitated by the role played by transnational networks, in particular by the transnational feminist movement. Further, they suggest a major shift in the nature and the locus of global politics and national policymaking (True, J. \& Mintron, M., 2001).

Gender mainstreaming is an approach that situates gender equality issues at the center of broad policy decisions, institutional structure and resource allocations, and includes women's as well as men's views and priorities in making decisions about development goals and processes. It aims to ensure the recognition of gender issues by government agencies and other institutions on a sustained basis. It seeks to achieve equality between women and men in all aspects of life (CIDA, 2002).

Haddad ( 1995) explain that policy making has two dimensions namely the actors and the process. Historically the actor in policy making has been considered unitary and rational; more recently policy analysts have introduced the organizational (public interest) model and the personalistic (self-interest) model. The process element has fluctuated between a synoptic (comprehensive) approaches and an incremental approach. He recommends the following process

(i). Analysis of the existing situation.

(ii). The generation of policy options.

(iii). Evaluation of policy options.

(iv). Making the policy decision.

(v). Planning of policy implementation.

(vi). Policy impact assessment.

(vii). Subsequent policy cycles Haddad (1995).

There are many approaches to analyzing and developing policy and programs. Conducting good quality policy and program usually requires following a sequence stages or steps. For many people applying these steps is a regular part of their routine work but may not be clearly articulated or documented. These steps are

1. Identify the issue 
2. Defined Desired Goals and outcomes

3. Research and consultation

4. Analyze options and make recommendations

5. Communicate the policy/program decision

6. Implement and Evaluate the policy/ program (Women's Policy Office, 2003).

Pakistan adopted the policy of gender mainstreaming because it is signatory to international and national commitments. Achieving gender equality in the health sector implies eliminating unnecessary, avoidable and unjust inequities between women and men, girls and boys. Gender is one of the cross-cutting themes being addressed through the United Nations "Delivering as One" initiative in Pakistan, and provides an appropriate entry point for promoting United Nations commitment and capacity to address gender inequality (WHO, 2014).

The Gender Reform Action Plan (GRAP) evolved from a donor support project in 2002 and became a 100\% Public Sector Development Plan (PSDP) project of the GOP in 2005 through PC-1. It also faced problems such as delay due to recruitment of staff, weak ownership at the Ministry level and political influences ( Yazdani \& Jawad, 2010). A report of National Assembly Standing Committee 2009 stated that The Gender Reform Action Plan (GRAP) is a GoP initiative to promote women's access to economic, political and social empowerment, at the national, provincial and district levels. Its key reform areas are institutional restructuring; policy, budgeting and public expenditure mechanism, women's employment in public sector, political reforms. The Committee recommended that GRAP required a monitoring mechanism for timely and appropriate use of funds. In this regard, the Committee suggested that a proposal be developed to transfer GRAP and CEDAW projects from the development to non-development funds, eventually becoming part of the MoWD's regular activities and streamlining women's activities under the umbrella of the Ministry (National Assembly's Standing Committee on Women Development, 2009).

Cyan (2005) identifies differences in nature of proposals in federal and provincial GRAPs. For instance the federal GRAP deals with National Commission on the Status of Women (NCSW), Ministry of Women Development (MoWD), Election Commission and intergovernmental grants which the provincial GRAPs do not cover. Among the provinces the differences relate to the structure of Women Development Directorates (and/or Departments) and the number of new positions that they'll create at the provincial and local levels. GRAPs had an implementation timeframe of five years during which it suggested focus on gender in the written document, including identification of gender gaps in the sector, clear statements on how these gaps will be filled, guidelines and roadmap of how this will be achieved, in the short, medium and long run. Also it suggested 
recognizing women as group, making quantitative targets, provision of technical inputs from relevant ministries, ownership by political leadership and budget allocations.

\section{Methodology}

Internationally, there are plans and policies which are adopted by governments for gender equality. In case of Pakistan, the process is recent and in real life they are not showing the results that are expected. To understand this change at the national level, gender analysis of policies is selected as a unit of analysis to explore how much the claims that were made have been fulfilled and how much the policies in Pakistan have become gender sensitized. The main method of data collection is documentary analysis. The research is based on secondary data analysis including a range of documents associated with policy as well as published reports and statistics. The documents analyzed for this research are selected on the bases of relevance. Following documents are analyzed

1. Health Policy of Pakistan- 2009

2. Pakistan Economic Survey 2014-15

The procedure of data collection was simple and universal. A thorough search for project reports and policy studies was undertaken. It was content analysis as well as indicators analysis. Content analysis is "a wide and heterogeneous set of manual or computer-assisted techniques for contextualized interpretations of documents produced by communication processes in the strict sense of that phrase (any kind of text, written, iconic, multimedia, etc.) or signification processes (traces and artifacts), having as ultimate goal the production of valid and trustworthy inferences. It was checked that how many times the word "gender" is used and in which context (Tipaldo, 2014).

\section{Results and Discussion}

The results show that in health policy the gender component is included but superficially. The term gender has been used several times in the policy document but it lacks the actual meaning of it. For this research National Health Policy, 2009 document was analyzed. The draft identifies the challenges faced by health sector in Pakistan. It signifies that the overall health spending in Pakistan is very low level even when compared with other low income countries. The total annual health expenditures are Rs. 186 billion (USD 3.1 billion or nearly USD 19 per capita) or about $1.9 \%$ of the national GDP. Most of these expenditures are for curative care and over $80 \%$ of all health spending goes for treatments and only $16 \%$ for prevention services. 
The policy actions suggested to coup with it is for example federal and provincial governments will allocate budgets for health on the basis of per capita costs as determined by costing out the delivery of a nationally contextualized package of primary health care services. Most of these policy actions were suggested till the year 2015 but data shows that they are unable to be achieved yet.

Another challenge highlighted is people moving towards private health facilities. Over the years, the government has ceased to be the principal provider of essential health care. In this respect, the most recent data credibly show that when people are sick, they increasingly turn to the private sector for medical care. While this may be acceptable in principle, the market for health related services in Pakistan is completely unregulated. Regulating private health sector and providing appropriate incentives is need of the hour. Without adequate regulation and in the absence of appropriate incentives the private health sector is unlikely to make health care provision more efficient.

The policy draft explains that Pakistan has made concrete commitments to the Millennium Development Goals (MDGs). Through its major health intervention programs, the Ministry of Health has pursued practical strategies aimed at reducing: the under-five mortality rate from an estimated 140 in 1990 to a target of 52 by 2015 the infant mortality rate from an estimated 110 in 1990 to a target of 40 by 2015 the maternal mortality ratio from an estimated 530 in 1990 to a target of 140 by 2015 . According to WHO current statistics shows that under five mortality is 86 , maternal mortality 170 . The data is sex disaggregated and shows the gender parity.

In this draft 'gender' is used two times not specifically as an issue but referring to gender inequality and gender bias in the society as a whole. According to a study there are three levels of healthcare facilities: First, the primary healthcare that include the Basic Health Units (BHUs), Mother and Child Healthcare Centres and in some areas the Civil dispensaries. The second level of healthcare called secondary healthcare facilities are the district headquarter hospitals, and third are Tertiary level healthcare facilities such as federal and provincial teaching hospitals which are meant for preparing medical professionals and research. In short, the federal ministry of health along with its Planning and Development Unit formulates policies, which are mainly focused on clinical healthcare, paying less attention to other determinants of health and diseases lying outside the Biomedical model of health (Khan, 2006).

Pakistan Economic Survey 2014-15 recognize that Pakistan's progress on health related MDGs vary across different goals. Lady health workers coverage to be universalized by 2015 has increased significantly and the target seems to be achievable. The under- five mortality rate has declined moderately to 85.5 versus 
its targeted reduction of 52/1000 deaths. However, Pakistan's progress on maternal and child mortality rates is not suffice to meet the MDGs targets on account of a number of factors like illiteracy, food insecurity, inadequate nutrition and low financial allocation. The overall lack of progress can also be traced back to specific problems.

The above analysis was mainly focused on health sector but other studies show that different initiatives during the same time period also faced failure such as GRAP as a concept could not mature as an ostensible policy framework or tool of/for the Government of Pakistan either by its Executing Agency i.e. MOWD; its stakeholders i.e. its Federal Implementing Partners (FIP); its Implementer i.e. GRAP; and by its donors (Yazdani \& Jawad, 2010). Further, eliminating the social and economic hurdles that obstruct equality must be the foundation of every policy intention, otherwise policy initiatives will merely end up duplicating and reinforcing existing discrimination against marginalised sectors, especially women, minorities and the poor. This result in adverse policies which wrongly assume that some growth oriented economic strategy will, indirectly, lead to improvement in people's quality of life (Afiya, 2010).

\section{Conclusions}

The above analyses have also made clear that the policy planning processes are country-specific (even time bound) and are highly dependent on sectoral, economic and socio-political conditions and Interactions. Certain recurring factors could, however, be discerned that have strong implications for effective education and health planning. First, policy development should be based on solid knowledge along three dimensions: (a) a diagnosis of the sector itself drawing on data, research, experience and international knowledge; (b) contextual analysis of the economic, political, demographic, social and cultural conditions and prospects; and (c) an assessment of the interest groups, their rationalities and roles in change, and the processes through which trade-offs are accomplished among them. This contextual analysis may be influenced by external sources, but to be effective should be internalized and locally owned.

Second, before a policy decision is made, different viable policy options need to be generated. This is the easy part. What is more difficult is to construct scenarios around each option to determine requirements and consequences. Each scenario should be systematically analyzed and evaluated, not only in terms of the educational merit of the policy proposal but also in terms of its desirability (taking into consideration the multiplicity of interests involved), financial affordability, feasibility in terms of the implementation capacity of the country, and sustainability over a sufficient period of time to show results. The selection of the optimal option will continue to be ultimately political, but a rigorous analysis of 
different scenarios, based on reasonably good knowledge, enlightens the political decision-making process and allows the different interest groups to be engaged in consultations in a meaningful manner.

Third, how radical and comprehensive should a policy choice be? It is not obvious that an incremental issue-specific approach is always superior to a comprehensive strategic approach. Certainly, a comprehensive strategic reform is unlikely to succeed where the absorptive capacity of the country is meager or where there is no demonstrated demand for the policy. A step-by-step approach allows experimentation and adjustment and does not have high political and institutional demands. On the other hand, this approach may lead to 'low risk' quick-fixes, and inadequate investment in terms of political capital and other resources to carry the reform off successfully. The success stories of the case studies have shown that to solve sector-wide problems in the context of political and economic demands, it is prudent to start with a limited incremental phase, but this should be succeeded in time by a comprehensive strategic approach. The timing and speed of this evolution should be gauged to the degree of acceptability of the reform by the stakeholders, and the implementation capacity of the system.

Fourth, whether a policy reform is incremental or comprehensive, its true test comes during planning and implementation. Here, three factors proved to be crucial: (a) Macro planning, to address national problems and provide an overarching blueprint, must be complemented (and not substituted) by micro planning at the project and local level; (b) Mobilization of political and public support should be deliberately planned for and sought and, during the planning and implementation stage, stakeholders should be actively involved; (c) Planning should be flexible, leaving room for modifications during implementation.

Fifth, when a policy goes into effect, it is not the end of the policy-planning process; it is the beginning of a new chapter. Policy reforms should be systematically assessed, preferably with a built-in mechanism, in terms of their impact; is it achieving what was expected of it at the time of its adoption? While implementation mechanisms need to be reviewed continuously, policies themselves should be allowed to mature before a judgement is passed on their impact. Even then, implementation problems should not be mistaken for inadequacies of the policy itself. Even if impact assessment concludes that the desired changes have been successfully implemented, policy-makers and planners should maintain vigilance for new changes required, given the rapid pace of contemporary society and the intimate links between an educational system and its environment.

Finally, if a policy is determined to be ineffective, it should not be allowed to linger while new policies are introduced alongside. Instead, a new cycle of 
rigorous policy design, formulation and planning must be initiated. In conclusion, educational development is extraordinarily complicated because it involves and affects a large number of beneficiaries and providers, as well as political figures, all of whom have a stake in the process and the outcome. Added to this is the long gestation period for any policy to realize its objectives. For these reasons, policy change should not be introduced lightly, nor should it be abandoned without careful examination.

\section{References}

Afiya, S. Zia (2010). A POLICY FRAMEWORK FOR WOMEN'S EQUAL RIGHTS (2010) NCSW, Islamabad http://www.ncsw.gov.pk/prod_images/ pub/APolicyFramework.pdf

CIDA (2002). Transforming Government to Think and Act GAD http://www.pcw.gov.ph/publication/transforming-government-think-andact-gad

Cyan, M. R. (2005). Study of the Recent Budgetary and Planning Reforms in Pakistan, Government of Pakistan Finance Division Gender Responsive Budgeting Initiative (GRBI) http://www.grbi.gov.pk/documents/ budgetaryreform.pdf

Haddad, Wadi, D. (1995). Education Plicy-planning Process: An Applied Framework, UNSESCO, International Institute for Educational Planning, www.unesco.org/education/pdf/11_200.pdf

JICA (2008). Country Gender Profile, http://www.jica.go.jp/pakistan/english/ office/others/pdf/CGP_02.pdf

Khan, M.M. (2006). Health Policy Process and Health Outcome: The Case of Pakistan: Health Policy Analysis, Eastern Mediterranean Health Journal, Pakistan Economic Survey 2014-15, http://www.finance.gov.pk/ survey_1415.html

National Assembly's Standing Committee on Women Development, (2009). http://www.na.gov.pk/uploads/documents/1303527397_649.pdf

Rizvi, N. Khan, K.S. \& Shaikh, B.T. (2014). Gender: Shaping Personality, Lives and Health of Women in Pakistan in BMC Women's Health, pp.14-53.

Tipaldo, G. (2014). L'analisi del contenuto e i mass media. Bologna, IT: Il Mulino. p.42. 
True, J. \& Mintron, M. (2001). Transnational Networks and Policy Diffusion: The Case of Gender Mainstreaming, International Studies Quarterly, Volume 45, Issue 1, pp. 27-57.

WHO (2014). Gender in Health And Development http//www.emro.who.int/pak/ programmes/gender-a-health.html

Women's Policy Office (2003). Guide Lines for Gender Inclusive Analysis, An Integrated Approach to Policy/Program Development, Women's Policy Office (2003-2004), Government of Newfoundland and Labrador, http://www.exec.gov.nl.ca/exec/wpo/publications/20032004annreport.pdf

World Health Organization (WHO) (2003). Gender analysis in health: A review selected tool, retrieved from http://www.who.int/gender/documents/ gender/9241590408/en/

Yazdani, F. \& Jawad, S. (2010). Review of the Implementation of Gender Reform Action Plan (GRAP). http://www.jica.go.jp/english/our_work/ thematic_issues/gender/background/pdf/e10pak.pdf

Dr. Shagufta Nasreen is an Assistant Professor in the Centre of Excellence for Women's Studies, University of Karachi.

Dr. Aliyah Ali is an Assistant Professor in the Centre of Excellence for Women's Studies, University of Karachi. 